\title{
Mutagenic effect of phosphemide for induction of mutations of Hordeum vulgare L. and Linum usitatissimum L.
}

\author{
Bomé N.A. ${ }^{1 *}$, Korolev K.P. ${ }^{1}$, Tetyannikov N.V. ${ }^{1}$, Weisfeld L.I. ${ }^{2}$, Kolokolova N.N. ${ }^{1}$ \\ ${ }^{1}$ Tyumen State University, Tyumen, Russia \\ ${ }^{2}$ Emanuel Institute of Biochemical Physics, RAS, Moscow, Russia \\ *e-mail:bomena@mail.ru
}

Genetic erosion of plants leads to a reduction in the number of varieties, therefore, to a decrease in the productivity of agrocenoses at changing environmental conditions. The use of induced mutants in breeding programs led to the creation of 3222 varieties of 170 different plant species in more than 60 countries of the world. The significance of researches in this area increases significantly with the mutations induction at using a new or insufficiently studied mutagenic factor. The goal of our research is the development of the scientific basis for the application of the chemical mutagen phosphemide in the seed's treatment of barley (Hordeum vulgare L.) and flax (Linum usitatissimum L.). A prerequisite for the use of new methods is the presence of a mutant population. In experimental work should consider differences in the set of chromosomes: at Hordeum vulgare $2 n=14$; and at Linum usitatissimum $2 n=30$. We have substantiated various concentrations for treating barley seeds $(0.002,0.01 \%)$ and flax $(0.005,0.01,0.1 \%)$. The effectiveness of the mutagenic factor was determined by the sensitivity of barley and flax to the phosphemide in $M_{1}$, the frequency and spectrum of mutations in the $M_{2}$ and $\mathrm{M}_{3}$ as in laboratory conditions so in field experience. The physiological status of seeds and the variability of plant morphometric parameters in ontogenesis are among the informative criteria. The express-diagnostics of chlorophyll content in leaves at different stages of ontogenesis was tested. Based on the readings of the SPAD 502 chlorophyll optical counter (Minolta Camera Co., Japan), significant differences were found in the accumulation and degradation of chlorophyll in the control and after phosphemide. The content of the mass fraction of starch and amylose in the barley grain was determined by the genotype and the concentration of mutagen. The mutagenic effect of phosphemide was confirmed by mutations in barley (10) and flax (10). 